\title{
Research Article \\ FREQUENCY OF MUTATION IN ISONIAZID RESISTANT ISOLATES OF Mycobacterium tuberculosis COMPLEX FROM WESTERN MAHARASHTRA INDIA
}

\author{
HATOLKAR SWARUPA M., MISRA RABINDRA NATH, GANDHAM NAGESWARI R., ANGADI KALPANA, JADHAV SAVITA V. AND \\ GUPTA NEETU
}

Dr D. Y. Patil Medical College, Hospital and Research Centre, Dr D. Y. Patil Vidyapeeth, Pimpri, Pune 411018

*Corresponding Author: Email-rn.misra@dpu.edu.in, patilsv78@gmail.com

Received: January 16, 2018; Revised: March 09, 2018; Accepted: March 10, 2018; Published: March 30, 2018

\begin{abstract}
Introduction: The alarmingly worsening scenario of Multi drug-resistant tuberculosis (MDR-TB) call for urgent need for a simple method for the rapid detection of drug-resistant TB. In MTB katG mutations are major cause of INH resistance. The usefulness of INH, a key component of short-course chemotherapy of tuberculosis, is threatened by the emergence of drug-resistant strains of MTB with mutations in the katGgene. Objective: This study is an effort to study the frequency of mutations in INH in Western Maharashtra, India. Methods: Samples were processed for two molecular methods, GenoTypeMTBDRplus (LiPA) and Dideoxy Sanger Sequencing. Samples processed for DNA extraction, nested PCR reaction was done by annealing at $55^{\circ} \mathrm{C}$ with specific primers. After confirmation of band on Gel Doc, Sequencing was done with one primer. Sequencing was also done for inhA and inhA promoter region. Result: Major mutation found was S315T i.e. ser is replaced by thr at 315 positions. We could find other mutation at different positions. Conclusion: Molecular tests are rapid and accurate. S315T can be potential genetic marker for isoniazid resistance.
\end{abstract}

Keywords- MTB, katG, Isoniazide mutations, Genetic marker S315T.

Citation: Hatolkar Swarupa M., et al., (2018) Frequency of Mutation in Isoniazid Resistant Isolates of Mycobacterium tuberculosis Complex from Western Maharashtra, India. International Journal of Microbiology Research, ISSN: 0975-5276 \& E-ISSN: 0975-9174, Volume 10, Issue 3, 1043-1045. DOI: http://dx.doi.org/10.9735/0975-5276.10.3.1043-1045

Copyright: Copyright@2018 Hatolkar Swarupa M., et al., This is an open-access article distributed under the terms of the Creative Commons Attribution License, which permits unrestricted use, distribution and reproduction in any medium, provided the original author and source are credited.

Academic Editor / Reviewer: Dr Jalal Ali Bilal, Dr Sourav Sharma, Dr Abheepsa Mishra

\section{Introduction}

The alarmingly worsening scenario of Multi drug-resistant tuberculosis (MDR-TB) call for urgent need for a simple method for the rapid detection of drug-resistant TB in clinical settings. Testing of mycobacterial culture and drug susceptibility testing (DST) capacity are limited in resource-scares countries; leading to inadequate treatment and development of favoring resistance [1].

Isoniazid (INH) is an effective first-line anti-tuberculosis drug. KatG, a catalaseperoxidase enzyme, converts $\mathrm{INH}$ to an active form in Mycobacterium tuberculosis, and katG mutations are major causes of INH resistance $[1,2]$. The usefulness of $\mathrm{INH}$, a key component of short-course chemotherapy of tuberculosis, is threatened by the emergence of drug-resistant strains of MTB with mutations in the katG gene and is associated with clinically significant levels of INH resistance [3].

INH has a simple chemical structure consisting of hydrazide group attached to a pyridine ring, but its mode of action is very complex. One of the proposed mechanisms is that it enters the M. tuberculosis as a prodrug by passive diffusion and is activated by catalase-peroxidase enzyme, encoded by katG [4]. Some studies shown that is involved in biosynthesis of mycolic acid [5].

Objective: This is an effort to study the frequency of mutations in INH mono resistant isolates and in MDR strains of MTB complex with two different molecular methods, LiPA and Dideoxy sanger sequencing for single nucleotide polymorphism from Western Maharashtra.

\section{Material and Methods}

Study was conducted in tertiary care hospital from Dr. D.Y. Patil Medical College,
Hospital \& Research Centre, Pune India over a period of two years i.e. January 2014- December 2016.

Samples were processed for ZN staining before and after Decontamination of the sample with NALC-NaOH method. [6]

Samples were processed for two molecular methods Line Probe Assay (LiPA), [7] (Hain Life sciences GmbH, Nerhren, Germany) and Sanger Sequencing (3130 genetic analyzer, Applied Biosystems) [8]. Study was done on monodrug and multidrug resistant strains of MTB complex.

Two different methods were chosen as LiPA was available at institute and it gives information about MTBC complex \& drug resistance in shorter time but could not provide information about exact Single nucleotide polymorphism (SNP). To confirm the exact SNP mutation and validation of LiPA results Sanger sequencing was the best method available in collaboration.

\section{Inclusion criteria}

Monodrug and Multidrug resistant isolates (growth cultures or excess amount availability of decontaminated sediment).

LiPA test was criteria along with clinical correlation from suspected cases of tuberculosis; clinical samples; Sputum, BAL Pleural Fluid, Tissue, Pus, CSF.

Extracted DNA required for both molecular testing could be possible only with grown cultures or excess amount of decontaminated sediment

LiPA was performed as per manufacture's instruction.

\section{Dideoxy Sanger Sequencing}

Isolation of genomic DNA

DNA was isolated using QIAGEN kit DNAeasy (CAT.NO. 56404) as per 
manufacturer's instructions.

\section{kat-G genotyping \\ PCR Primers and Amplicon size}

KatG gene amplification using nested PCR primers targeting for catalaseperoxidase gene of M. tuberculosis was performed. Nested primers included one outer set of primers and one inner setoff primers. Upstream outer primer $[9,10]$ and downstream outer primer 5'TAAGCGGGATCTGGAGAA3', and inner primer set for the second round consisting of upstream primer 5'GTCCTTGGCG GTGTATT3' and downstream primer: 5'CATGAACGACGTCGAAAC 3'. Outer primer set codes for $547 \mathrm{bp}$ region from KatG gene, while the inner primer set codes for a region $304 \mathrm{bp}$ within the $547 \mathrm{bp}$. Analysis of the results on agarose ge electrophoresis and visualization of the amplified products over the GelDoc - XR (BioRad) was done for 2nd round amplification products.

\section{PCR Reaction setup}

PCR mix typically consisted of $50 \mathrm{uL}$ of final reaction volume containing $10 \mathrm{~mm}$ Tris- $\mathrm{HCl}(\mathrm{pH} 8.3), 50 \mathrm{~mm} \mathrm{KCl}, 2.5 \mathrm{~mm} \mathrm{MgCl} 2,0.01 \%$ (w/v) gelatin, $50 \mathrm{pmol}$ of respective primers (mentioned above), $2.5 \mathrm{nmol}$ of each of the four deoxy nucleoside triphosphates (dATP, dCTP, dGTP and dTTP), 1U of Taq DNA polymerase (Invitrogen, USA). The PCR cycle conditions were: Initial denaturation at $95^{\circ} \mathrm{C}$ for 5 minutes, $95^{\circ} \mathrm{C}$ for 1 minute to denature the DNA, then cooled to $55^{\circ} \mathrm{C}$ for $45 \mathrm{sec}$, heating to $72^{\circ} \mathrm{C}$ for $1 \mathrm{~min}$ for extension, cycle repeated 30 times with final incubation at $72^{\circ} \mathrm{C}$ for $10 \mathrm{~min}$, for nested PCR $94^{\circ} \mathrm{C}$ for $30 \mathrm{~s}$ to denature the DNA, then cooled to $52^{\circ} \mathrm{C}$ for $30 \mathrm{~s}$, heating to $72^{\circ} \mathrm{C}$ for $30 \mathrm{sec}$ for extension, cycle repeated 35 times with final incubation at $72^{\circ} \mathrm{C}$ for $10 \mathrm{~min}$. Amplicons from first PCR were used as template for second round nested PCR.

\begin{tabular}{|c|c|c|c|c|}
\hline \multicolumn{5}{|c|}{ Table-1 PCR REACTION /PRIMERS } \\
\hline Mutation & Primer & $\begin{array}{c}\text { Amplicon } \\
\text { size }\end{array}$ & $\begin{array}{l}\text { Annealing } \\
\text { Temp }\end{array}$ & $\begin{array}{l}\text { Mutation } \\
\text { position }\end{array}$ \\
\hline $\begin{array}{l}\text { katG } \\
(1)\end{array}$ & $\begin{array}{l}\text { Fw: 5' CGTGATCCGCTCATAGAT3' } \\
\text { Rv: 5' TAAGCGGGATCTGGAGAA 3' }\end{array}$ & $547 \mathrm{bp}$ & $55^{\circ} \mathrm{C}$ & S315T \\
\hline $\begin{array}{c}\text { katG } \\
\text { (nested) }\end{array}$ & $\begin{array}{l}\text { Fw: 5' GTCCTTGGCGGTGTATT 3' } \\
\text { Rv: 5' CATGAACGACGTCGAAAC 3' }\end{array}$ & 304 bp & $52^{\circ} \mathrm{C}$ & S315T \\
\hline $\begin{array}{c}\operatorname{lnh} A \\
\text { promoter }\end{array}$ & $\begin{array}{l}\text { Fw: 5' GGCACGTACACGTCTTTATGTA } \\
\text { 3' } \\
\text { Rv: 5' GGTGCTCTTCTACCGCCGTGAA } \\
\text { 3' }\end{array}$ & $479 \mathrm{bp}$ & $55^{\circ} \mathrm{C}$ & $\begin{array}{l}\mathrm{C} 15 \mathrm{~T} / \\
\mathrm{A} 16 \mathrm{G}\end{array}$ \\
\hline inhA & $\begin{array}{l}\text { Fw: 5' AAACGGATTCTGGTTAGCGG 3' } \\
\text { Rv: 5' CGGGTTGATGCCCATCCCGG 3' }\end{array}$ & $300 \mathrm{bp}$ & $55^{\circ} \mathrm{C}$ & $\mathrm{T} 8 \mathrm{C} / \mathrm{T} 8 \mathrm{~A}$ \\
\hline
\end{tabular}

Table-2 Association of mutation pattern in LiPA and Sequencing

\begin{tabular}{|c|c|c|c|c|}
\hline Gene & $\begin{array}{c}\text { LiPA failing } \\
\text { Wild type } \\
\text { band }\end{array}$ & $\begin{array}{c}\text { Codon } \\
\text { analyzed }\end{array}$ & $\begin{array}{c}\text { Developing } \\
\text { mutation band }\end{array}$ & Mutation \\
\hline katG & katG WT & 315 & KatG MUT 1 & S315T 1 \\
\hline & & & KatG MUT 2 & S315T 2 \\
\hline inhA & inhA WT1 & -15 & inhA MUT 1 & C15T \\
\hline & & -16 & inhA MUT 2 & A16G \\
\hline & inhA WT2 & -8 & inhA MUT 3A & T8C \\
\hline & & & inhA MUT 3B & T8A \\
\hline
\end{tabular}

Results

Polymerase Chain reaction result:

Each sample show PCR amplicons of desired size on agarose gel

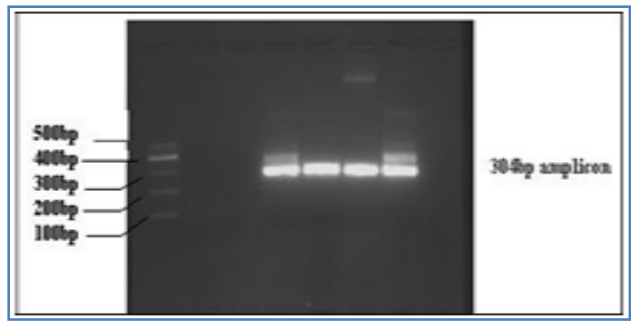

Fig-1 Kat-G gene PCR IMAGE: 1\% (WN) Agarose Gel electrophoresis: Lane 1: 500 bp DNA marker; Lane 2: NTC; Lane 4 and 8: sample PCR Products

\section{DNA sequencing}

Sequences were aligned with katG REF or wild type sequence gene usinghttp://www.genome.jp/tools-bin/clustalw(Kyoto University Bioinformatics Center) [11]

Following are the genes sequenced and are analyzed for drug resistance using different online available tools and databases.

https://umr5558-bibiserv.univ-lyon1.fr/mubii/mubii-select.cgi

https://tbdreamdb.ki.se/Info/Default.aspx [13], http://tuberculist.epfl.ch/index.htm] [14],

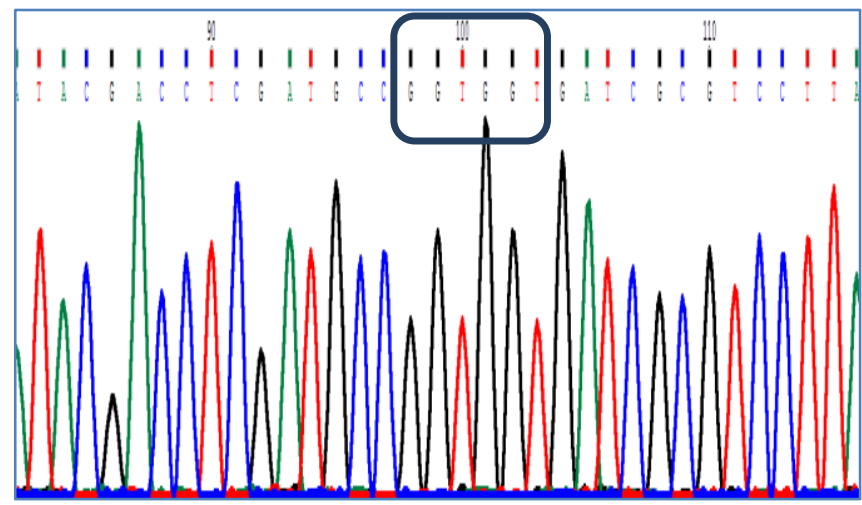

Fig-2 Mutation site for S315T Mutation S315T/GCT-GGT

Total 50 samples processed for Line Probe assay. Male to Female ratio was 26:24.Out of 50 samples,38 were Pulmonary samples and 12 Extra-Pulmonary samples. ZN Staining was positive in 34 samples and 16 were Negative. From these 50 samples 30 samples were further processed for sequencing which were observed to be resistant for isoniazid by LiPA. From 21 MDR sequenced samples 19 showed only S315T mutation and 2 samples showed more than one mutation in addition to S315T. One sample showed N218K, V230A and T108C at promoter site. Another sample showed only G99T promoter mutation. From 9 mono resistant sequenced samples 5 showed S315T mutation, one sample showed only C101T promoter site mutation and rest did not show any mutations.

Sequences were credited to NCBI data base with following

\section{NCBI Accession numbers}

Bankit 2051477 MG019932 - MG019937

Bankit 2051485 MG019938 - MG019947

Bankit 2051500 MG019948 - MG019955

\section{Discussion}

The distribution and frequency of drug resistance mutations are variable across regions and countries. The frequency of katG mutation ranged from $58.5 \%$ to $93.7 \%$ and for inhA is $4.7 \%$ to $79.4 \%$. The mostly commonly mutated katG locus was katG315 and for inhA was 15 [15]. Genotype MTBDRplus were relatively rapid and simple method for detection of drug resistant TB but the disadvantage of this test is resistance detection is available for limited number of mutations. LiPA is also very much useful in Extra pulmonary TB also Other rapid molecular method as GeneXpert cannot detect the INH resistance. GenProbe can detect MTB complex for extra pulmonary samples but cannot detect drug resistance $[16,17]$ Phenotypic studies were not possible if there was contamination or less colony number for preparation of inoculum. Challenge is to diagnose extra-pulmonary tuberculosis even for the most practiced clinicians as clinical manifestations are vague, non-specific and typical chest radiograph findings may not be evident till late in the disease. Phenotypic methods for mycobacteriological culture and drug susceptibility testing are slow and cumbersome. Newer techniques for rapid detection of MTB and its anti-TB drug resistance have therefore become a priority hence with the development of molecular tests e.g., LiPA are most advanced [18] S315T mutations are the common katG mutations observed in this study correlates with the other studies and commonly associated with high level INH resistance [19]. Studies have revealed that mutation in katG gene is responsible for $60-70 \%$ of isoniazid resistant strains. A study by Negi et. al., in India reported $74.19 \%$ of S315T katG mutation in MTB strains from Delhi [20]. But in contrast the 
Ser315Thr mutations accounted for $52-64 \%$ of strains in Central Asia. There is need for development of kits targeting more resistant gene mutations, possibly targeted for each specific geographic region. Two different mutations of katG observed in this study were $\mathrm{N} 218 \mathrm{~K}, \mathrm{~V} 230 \mathrm{~A}$ and different promoter mutations were also observed as C101T,T108C,G99T. This insists for more mutation studies to be done [21]. A study done by Hazbon et al indicated that most studies examined relatively small numbers of isolates or failed to include sufficient number of drug susceptible controls to demonstrate statistically significant associations [22].

Conclusion: S315T can be potential genetic marker for isoniazid resistance. These mutations can be rapidly evaluated by rapid molecular diagnostic methods as LiPA.

Application of the research: Early detection of resistant strains of Mycobacterium tuberculosis infection will help in the institution of suitable therapy and also helps to reduce treatment failure and increase of resistant strains.

Research category: MDR Mycobacterium tuberculosis

\section{Abbreviation:}

MDR: Multidrug resistant

Acknowledgement / Funding: The authors are thankful to Dr D. Y. Patil Vidyapeeth, Pimpri, Pune 411018. Author also thankful to geneOm biotechnologies Pvt. Itd, Pune Author highly grateful to technical support of Swati Bhirange for isolation, Yashawant Chavan and Sharad Pawar for sequencing and analysis.

\section{*Research Guide or Chairperson of research: Dr R. N. Misra}

University: Dr D. Y. Patil Vidyapeeth, Pimpri, Pune 411018

Research project name or number: PhD Thesis

Author Contributions: All author equally contributed

Author statement: All authors read, reviewed, agree and approved the final manuscript

\section{Conflict of Interest: None declared}

Ethical approval: This article does not contain any studies with human participants or animals performed by any of the authors.

\section{References}

[1] Zhang L., et al., (2011) Molecular Biology Reports, 38(3), 2185-2192.

[2] Ando H., et al., (2010) Antimicrobial Agents and Chemotherapy, 54(5), 793-1799.

[3] Jeeves R.E., et al. (2015) PloS one, 10(9), e0138253.

[4] He X., Alian A. and de Montellano P.R.O. (2007) Bioorganic \& Medicinal Chemistry, 15(21), 6649-6658.

[5] Ramaswamy S.V., et al., (2003) Antimicrobial Agents and Chemotherapy 47(4), 1241-1250.

[6] Revised National Tuberculosis Control Programme [RNTCP] Manual 2009

[7] Barnard M., et al., (2012) Journal of Clinical Microbiology, 50(11), 3712-3716.

[8] Kim S.K., et al., (2008) The FEBS journal, 275(19), 4824-4835.

[9] Miotto P., et al., (2006) Journal of Clinical Microbiology, 44(7), 24852491.

[10] Ramirez M.V., et al., (2010) Journal of Clinical Microbiology, 48(11), 4003-4009.

[11] Sandgren A., et al., (2009) PLoS Med., 6(2), 0132-0136.

[12] Zhang Y., et al., (2011) J Bacteriol.,5591-5592.

[13] Han et al., (2015) Standards in Genomic Sci.,78.

[14] Flandrois et al., (2014) BMC Bioinformatics, 107.
[15] Jaksuwan R., et al., (2017) Infection and Drug Resistance, 10, 167.

[16] Vashistha H., et al., (2017) Indian Journal of Tuberculosis, 212-218

[17] Singhal R., et al., (2017) Journal of Epidemiology and Global Health, 175-180

[18] Jadhav S.V., et al., (2013) Journal of Clinical and Diagnostic Research, JCDR, 7(9), 1996.

[19] Lin Z., et al., (2017) Borneo Journal of Medical Sciences (BJMS), 2017, 15.

[20] Negi S.S., et al., (2006) Indian Journal of Experimental Biology, 547553.

[21] Vilchèze C. and Jacobs W.R. (2014) American Society of Microbiology, 431-453.

[22] Alland D., et al. (2007) Journal of Clinical Microbiology, 45(1), 39-46. 